\title{
Nerve Growth Factor Infusion in the Primate Brain Reduces Lesion-Induced Cholinergic Neuronal Degeneration
}

\author{
Mark H. Tuszynski, ${ }^{1}$ Hoi Sang U, ${ }^{2}$ David G. Amaral, ${ }^{1,3}$ and Fred H. Gage' \\ Departments of ${ }^{1}$ Neurosciences and ${ }^{2}$ Neurosurgery, University of California, La Jolla, California 92093, and ${ }^{3}$ The Salk \\ Institute, La Jolla, California 92037
}

\begin{abstract}
NGF is a protein that promotes survival, differentiation, and process extension of selected neuronal populations during development and, in some cases, in the mature organism. Previous lesion and aging studies in the rat have shown that intracerebroventricular NGF infusions can prevent degenerative changes in basal forebrain cholinergic neurons. We sought to determine whether salutory effects of NGF occur in the primate brain. Cholinergic fibers of the septohippocampal projection in the primate were surgically transected, followed by infusion of either a vehicle or an NGF solution into the ventricular system for a 4-week period. Quantification of cholinergic neurons in the medial septal nucleus at the end of the infusion period demonstrated that only 45 $\pm \mathbf{5} \%$ of cholinergic neurons could be identified after fornix lesions in vehicle-infused animals, whereas $80 \pm 6 \%$ of neurons were visible in NGF-treated animals. Thus, NGF substantially reduced lesion-induced cholinergic neuronal degeneration in the adult primate brain. This finding may be relevant to the hypothesis that NGF has potential use as a cholinergic "neurotrophic-factor therapy," given that loss of basal forebrain cholinergic neurons is common in Alzheimer's disease.
\end{abstract}

Since the discovery of nerve growth factor (NGF) $35 \mathrm{yr}$ ago, it has become the prototypical and most highly characterized neurotrophic factor (Levi-Montalcini et al., 1954; Thoenen and Barde, 1980; Levi-Montalcini, 1987). In the PNS, NGF supports sensory and sympathetic neuronal survival and axonal growth during development (Gundersen and Barrett, 1980). In the adult animal, regenerating peripheral axons can be attracted and guided by NGF (Gundersen and Barrett, 1980; Collins and Dawson, 1983). More recently, it has been shown that the CNS of adult mammals is also influenced by NGF. The CNS has been shown to contain NGF mRNA by in situ hybridization and by Northern blot analysis (Ayer LeLievre et al., 1983), NGF antigen by immunohistochemistry and radioimmunoassay (Greene and Shooter, 1980; Ayer LeLievre et al., 1983), biological activity by bioassay (Scott et al., 1981), and NGF receptors by immunocytochemistry and autoradiography (Tani-

\footnotetext{
Received Apr. 24, 1990; revised July 20, 1990; accepted July 23, 1990.

We are grateful to Barbara Mason, Kazunari Yoshida, Denise Anderson, Judy Tonilonis, Kris Trulock, and Stewart Zola-Morgan for valuable assistance. This work was supported in part by grants from the NIA $(5131,0353 \mathrm{~A}), \mathrm{NIH}, \mathrm{NIMH}$, the Pew Foundation, the Margaret and Herbert Hoover Foundation, and the Bristol-Myers Company.

Correspondence should be addressed to Fred H. Gage, Department of Neurosciences M-024, University of California at San Diego, La Jolla, CA 92093.

Copyright (C) 1990 Society for Neuroscience $0270-6474 / 90 / 113604-11 \$ 03.00 / 0$
}

uchi and Johnson, 1985; Richardson et al., 1986). Cholinergic neurons of the basal forebrain appear to be a primary target of NGF action in the brain, because radiolabelled NGF injected into cholinergic target regions such as the hippocampal formation is taken up by axons and retrogradely transported to cholinergic cell bodies in the basal forebrain (Schwab et al., 1979; Seiler and Schwab, 1984). Further, mRNA for NGF has been localized to target neurons of cholinergic cells in the forebrain of the rat. The highest levels of NGF in the CNS are found in regions innervated by cholinergic neurons of the septal complex and basal nucleus of Meynert (Sheldon and Reichardt, 1986), and the majority of NGF receptors in the adult rat and monkey brain are found on cholinergic neurons (Kordower et al., 1988; Batchelor et al., 1989).

Complete transection of the fimbria-fornix (FF) pathway in adult rats results in retrograde degeneration of both cholinergic and noncholinergic neurons located in the septal nuclei (Wainer et al., 1985; Gage et al., 1986; Hefti, 1986). One explanation for this degeneration is that septal neurons, which project to the hippocampal formation via the FF, become deprived of a critical supply of NGF normally provided by the target cells in the hippocampus. This hypothesis is supported by the fact that chronic intracerebroventricular infusion of NGF in rats with FF lesions prevents the degeneration of basal forebrain cholinergic neurons (Hefti, 1986; Williams et al., 1986; Kromer, 1987; Gage et al., 1988). NGF may also stimulate sprouting of axotomized cholinergic axons (Gage et al., 1988) and promote their regenerative capacity (Tuszynski et al., 1990a). Early retrograde degeneration studies in primates (Daitz and Powell, 1954) indicated that fornix transection in monkeys also leads to cell loss in the septal nuclei. Recent demonstrations that NGF receptors are localized to cholinergic neurons of the monkey septal nuclei (Kordower et al., 1988; Schatteman et al., 1988), and our interest in studying the extent to which NGF effects in the rat brain could be generalized to the primate brain prompted the development of a model for evaluating whether NGF infusion could prevent degeneration of cholinergic neurons in the primate.

\section{Materials and Methods}

The experimental procedure in our primate model is analogous to that used previously in the rat (Williams et al., 1986; Gage et al., 1988). Eight Macaca fascicularis monkeys were tranquilized with ketamine$\mathrm{HCl}(25 \mathrm{mg} / \mathrm{kg}, \mathrm{i} . \mathrm{m}$.) and deeply anesthetized with Nembutal (25-30 $\mathrm{mg} / \mathrm{kg}$ ) while heart rate, body temperature, and respirations were monitored. After placement of the monkey in a stereotaxic frame, the scalp was shaved, incised in the midline, and retracted laterally. Two craniotomies were performed.

Through the first, anterior craniotomy, a perfusion catheter was placed in the right frontal horn of the lateral ventricle. This craniotomy was performed $20 \mathrm{~mm}$ anterior to the intraural line and centered over the 


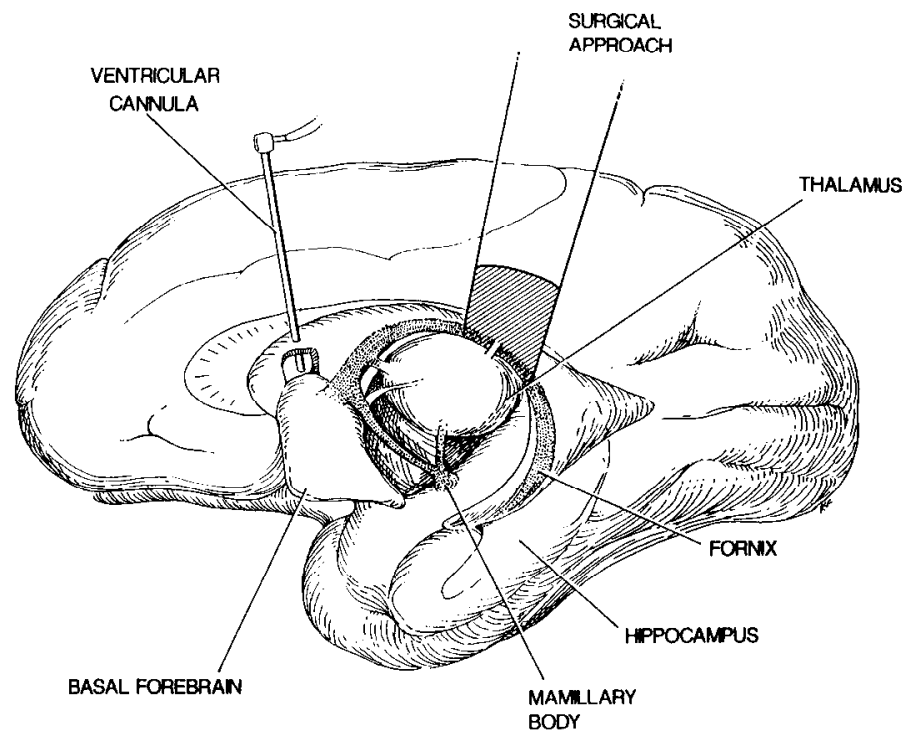

Figure 1. Drawing of medial aspect of primate brain in sagittal section. Projection from basal forebrain via fornix to hippocampus is shown. A window has been cut in the corpus callosum to reveal the infusion cannula in the frontal horn of the lateral ventricle. The cannula is connected by tubing to a subcutaneously placed osmotic pump. Also indicated is the surgical approach to the fornix at the level of the ventricular trigone, where the fornix is completely transected unilaterally: the hatched area indicates the parenchymal resection required for the surgical approach; the unhatched area indicates the area of brain retracted but not resected. right superior frontal gyrus. The dura was opened and retracted over the superior sagittal sinus. The entry point through the superior frontal gyrus into the lateral ventricle was identified stereotaxically at coordinates $+1.3 \mathrm{~mm}$ mediolateral $(\mathrm{M} / \mathrm{L}),+20 \mathrm{~mm}$ anteroposterior $(\mathrm{A} / \mathrm{P})$. $\mathrm{A}$ 28-gauge stainless-steel cannula (Plastic Prod. Co., Roanoke, VA), bent to a right angle $17 \mathrm{~mm}$ from its tip, was then introduced at these coordinates and lowered into the ventricle (Fig. 1). The proximal end of the cannula device was connected to kink-resistant vinyl tubing (Bolab Inc., Lake Havasu City, AZ) and filled with expcrimental solution (described below). Accurate dorsoventral placement of the cannula into the lateral ventricle was determined by electrophysiological recording of extracellular unit activity and verified by direct observation of free flow of the fluid column in the polyvinyl tubing into and out of the ventricular system. After accurate placement, the cannula was immobilized to the skull with dental acrylic, forming a cranioplasty over the cranial defect. Three small screws placed into the skull secured the acrylic platform. The tubing was then clamped pending completion of the second craniotomy.

The craniotomy for direct section of the fornix was then performed $4 \mathrm{~mm}$ anterior to the intraural line. The craniotomy was $20 \mathrm{~mm}$ in diameter and centered to the right of midline. The dura was once again incised and retracted over the contralateral hemisphere. This exposed the intcrhcmispheric fissure and cingulate gyrus. Cortical bridging veins that entered the superior sagittal sinus were preserved wherever possible. The ipsilateral hemisphere was then retracted from the falx cerebri to expose the underlying corpus callosum. The splenium and the overlying anterior cerebral arteries were identified, and a self-retaining retractor was used to expose the ipsilateral cingulate gyrus. A point $5 \mathrm{~mm}$ anterior to the tip of the splenium, on the surface of the cingulum, was selected for entry into the trigone of the lateral ventricle.

Using an operating microscope, the lateral ventricle was approached through the cingulum and corpus callosum. A bipolar coagulator and microsuction were used to remove a core of tissue pointing towards the roof of the lateral ventricle over a 5-mm area on the surface of the cingulum directly superior to the corpus callosum. An opening was created into the ventricular system, then enlarged to visualize the trigonal region. The choroid plexus was coagulated and excised to prevent hemorrhage. Trauma to the ependymal lining of the ventricle was avoided because ependymal veins are fragile and hemorrhage easily. In the ventricular trigone, the fornical bundle was easily identified as a 2-3mm-wide white, isolated bundle occupying the medial aspect of the trigone and overlying ependyma. After identification of its lateral and medial borders, the fornix was lifted from the ependyma and transected with either microscissors or the bipolar coagulator. Visualization of midline draining veins ensured complete medial transection of the fornix.

Upon completion of the fornical transection, fluid was irrigated into the ventricular cannula that had previously been placed into the frontal horn, providing further confirmation that the pump apparatus directly communicated with ventricular fluid. The dura was closed. A subcutaneous tunnel was made in the posterior nuchal region, and polyvinyl tubing attached to the intraventricular cannula device was then connected to an Alzet model 2ML4 osmotic pump (flow rate, $2.5 \mu \mathrm{l} / \mathrm{hr}$; capacity, $2 \mathrm{ml}$; Alza Corp., Palo Alto, CA). Into the pump was placed either a control (vehicle) solution consisting of artificial cerebrospinal fluid (CSF) with $0.1 \%$ primate serum and $50 \mu \mathrm{g} / \mathrm{ml}$ gentamycin (4 animals) or the same solution plus $180 \mu \mathrm{g} / \mathrm{ml}$ of $2.5 S$-mouse- $\beta$-NGF (4 animals). NGF was obtained from a commercially available source (Bioproducts for Science) and was qualitatively active in an in vitro PC12 neurite extension assay and a 2 -site enzyme-linked immunosorbent assay (ELISA) for NGF protein levels (see below).

The craniotomy wound was closed in layers, and each animal received postoperative antibiotics (ampicillin, $250 \mathrm{mg}$, i.m.) daily for $7 \mathrm{~d}$. At the end of a 4-week observation period, the animals were very deeply anesthetized with ketamine and Nembutal and perfused transcardially for $1 \mathrm{hr}$ with a $4 \%$ solution of paraformaldehyde in $0.1 \mathrm{M}$ phosphate buffer. Fixative was cleared from the brain by additional perfusion with $5 \%$ sucrose solution in the same buffer for $20 \mathrm{~min}$, and the brain was stereotaxically blocked in the coronal plane and cryoprotected for histological processing.

At the time of perfusion, osmotic pumps were removed from the animals, and the amount of fluid remaining in the pumps was measured. This allowed verification that the pumps had actually functioned during the infusion period. Residual pump fluid was assayed in 2 vehicleinfused and 3 NGF-treated animals for NGF activity using a 2-site ELISA sensitive to $5 \mathrm{pg} / \mathrm{ml}$ (Weskamp and Otten, 1987). In addition, just prior to perfusion, $3 \mathrm{cc}$ CSF were obtained from the cisterna magna in 2 vehicle-infused and 2 NGF-treated animals to assay NGF levels.

Brains were cut on a sliding microtome at $40-\mu \mathrm{m}$ intervals, and every sixth section through the septal complex was processed either by a Nissl method, a histochemical stain for AChE, or immunohistochemically with monoclonal antibodies directed against ChAT (kindly provided by Dr. Bruce Wainer) or NGF receptor (NGFr; kindly provided by Dr. Mark Bothwell; Batchelor et al., 1989). Immunohistochemical labeling was performed according to previously published protocols. Briefly, the ChAT procedure consisted of (1) 48-hr cold incubation of antibody against ChAT after 1:500 dilution with $0.1 \mathrm{~m}$ Tris-buffered saline containing $2 \%$ BSA, $20 \%$ rabbit serum, and $0.5 \%$ Triton X-100; (2) $1-\mathrm{hr}$ incubation in biotinylated rabbit anti-rat IgG (Vector Laboratories) diluted 1:50 with Tris-buffered saline containing $10 \%$ monkey serum and $0.2 \%$ Triton X-100; (3) 2-hr incubation in peroxidase-antiperoxidase (PAP) diluted 1:50 followed by rinse in $0.1 \mathrm{M}$ Tris-buffered saline and a second 2-hr PAP incubation; (4) treatment with a $0.05 \%$ solution of 3.3'-diaminobenzidine in phosphate buffer plus $0.015 \% \mathrm{H}_{2} \mathrm{O}_{2}$ for 15 min; and (5) osmium tetroxide intensification. Immunolabeled tissue sections were mounted onto gelatin-coated glass slides, air dried, and covered with Permount and glass coverslips.

Primary NGFr antibody specific for NGFr was obtained from a hy- 

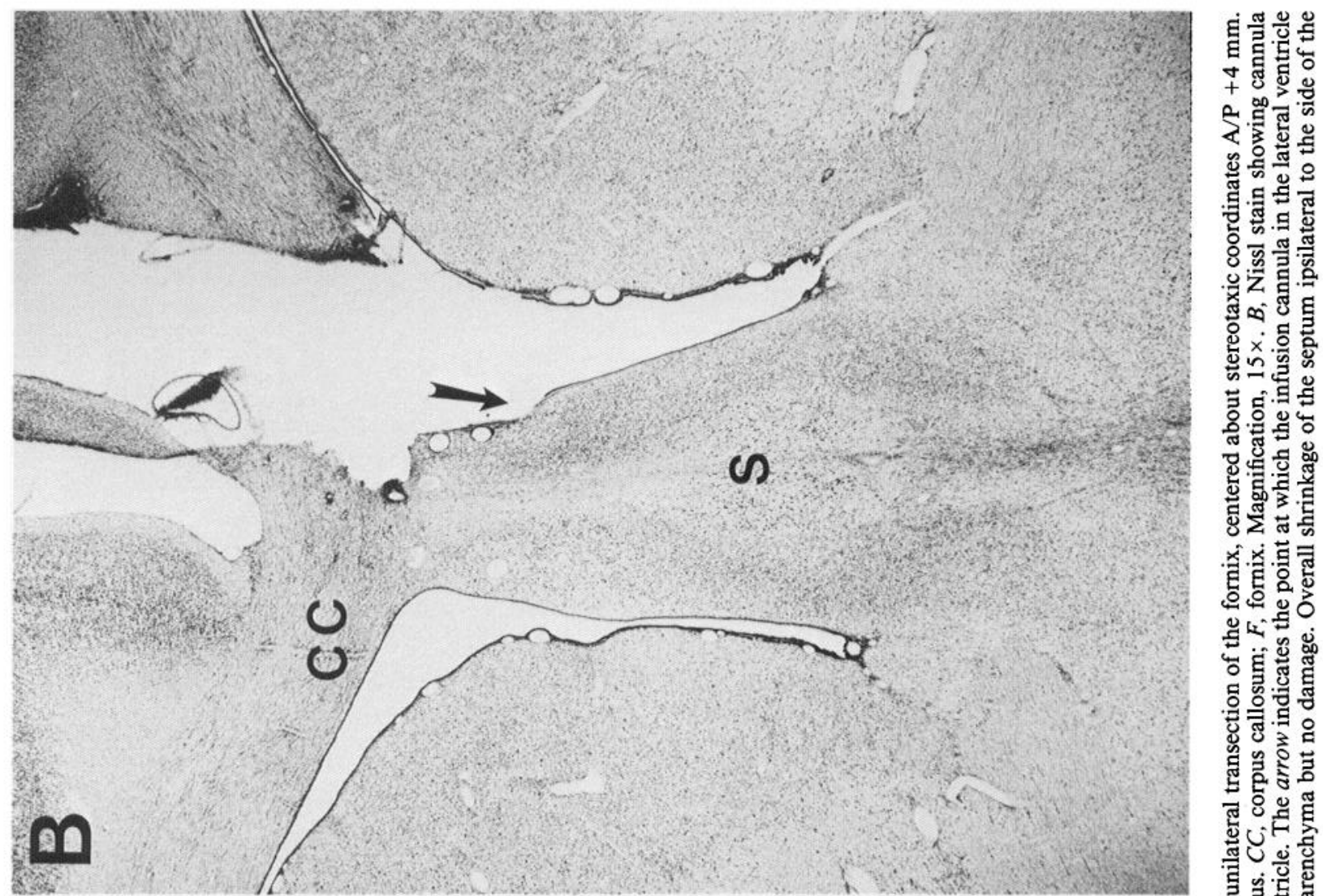

总离言需

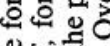

要

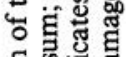

ㄷㅇㅇㅎㅁ금

정

놀

ते

ut

月

踢

들

兘它

역

政

돈을

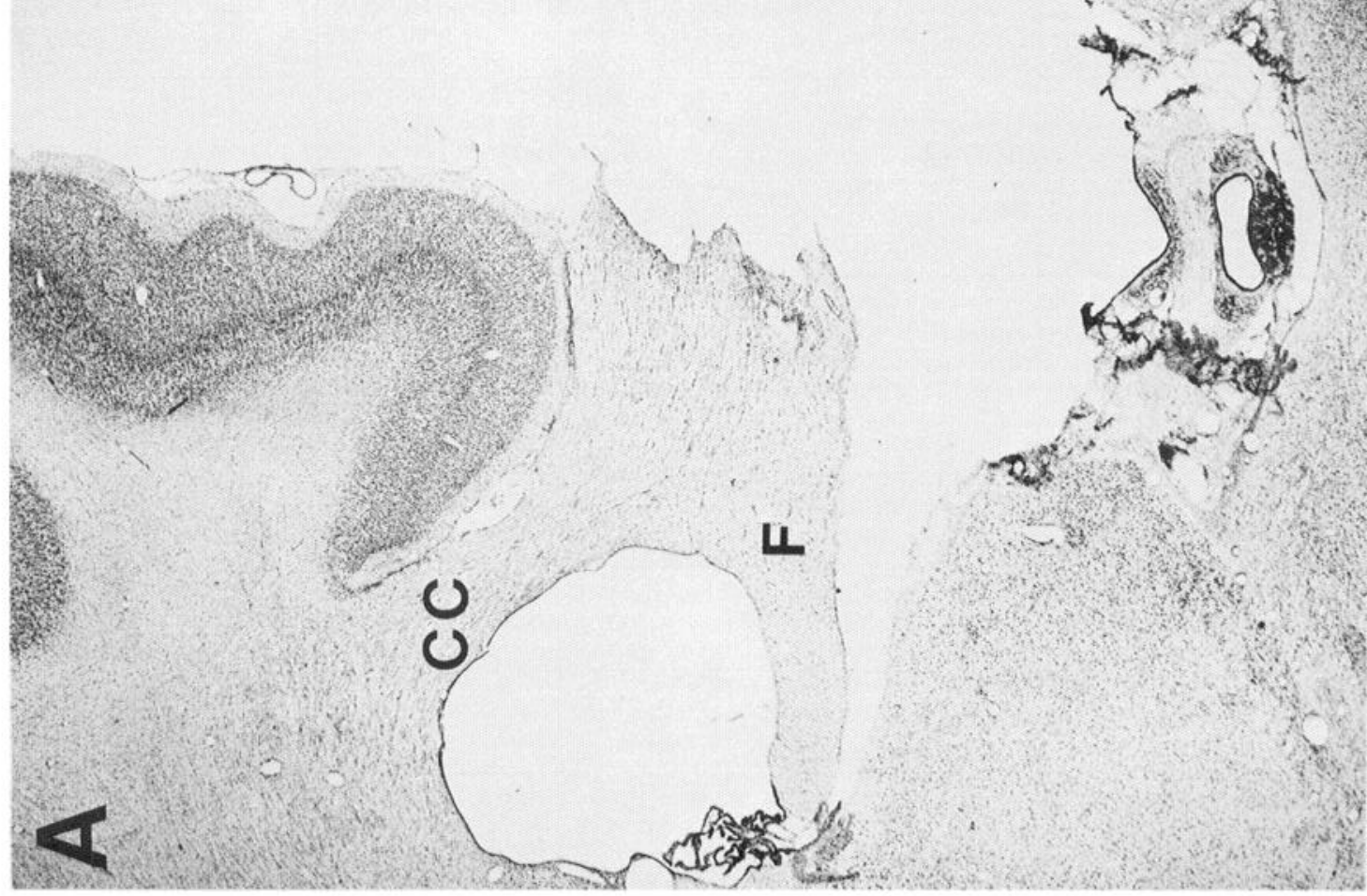

需

馬. 홀.

氙䨌 듕

乙

จे

웡

ํㅗㄹ

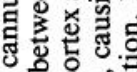

कह

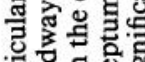

․ㅜㅇ영

호일

현령

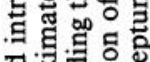


bridoma cell culture supernatant. The NGFr immunohistochemical procedure briefly consisted of (1) 48-hr cold incubation of antibody against NGFr after 1:2000 dilution with $0.1 \mathrm{M}$ Tris-buffered saline containing 1\% BSA, 1\% normal horse serum, and 0.4\% Triton X-100; (2) 1-hr incubation in biotinylated horse anti-mouse IgG diluted 1:200 in $2 \%$ normal horse serum and $2 \%$ normal monkey serum; (3) 1-hr incubation with avidin-biotinylated peroxidase complex (Vector Laboratories) diluted 1:1000 with Tris-buffered saline containing $1 \%$ goat serum; (4) treatment with a $0.05 \%$ solution of $3.3^{\prime}$-diaminobenzidine in imidazole buffer plus $0.005 \% \mathrm{H}_{2} \mathrm{O}_{2}$ and $2.5 \%$ nickel-ammonium sulfate for 15 min; and (5) osmium tetroxide intensification. Immunolabeled tissue sections were mounted onto gelatin-coated glass slides, air dried, and covered with Permount and glass coverslips.

The number of ChAT- and NGFr-labeled neurons was quantified independently by 2 observers, one of whom was blind to the experimental manipulations. All forebrain sections possessing medial septal neurons as a population distinct from the dorsally situated diagonal band were quantified (7-8 sections per animal), amounting to no fewer than 800 neurons counted per animal. Microscopic sections were analyzed with a $10 \times$ objective using a $0.5 \times 0.5-\mathrm{mm}$ counting grid. Cells labeled positively with peroxidase reaction product and possessing either (1) a cell body with emerging fiber or (2) a cell body with welldefined nucleus were counted. Cell counts on each side of the septum for all sections per animal were added, and results were expressed as percentage of neurons remaining labeled on the lesioned side compared to the unlesioned side of each animal.

Student's $t$ test was used to determine differences between the vehicleinfused and experimental groups (4 animals per group).

\section{Results}

Monkeys recovered from surgery within $12 \mathrm{hr}$ and tolerated the infusion period well. Animals did not dislodge the pumps or cannulae, infections did not occur, and no overt indications of toxicity were present.

In 7 of the 8 animals, histological examination revealed complete unilateral transection of the fornix (Fig. $2 A$ ); in the eighth animal (a vehicle-infused animal), a very thin remnant of the fornix remained intact, though cell degeneration in the septum was as extensive as that observed in other animals. In all animals, a tract was visible at the level of the septal complex extending through the cortex and underlying corpus callosum to enter the lateral ventricle, corresponding to the tract of the intraventricular cannula (Fig. $2 B$ ). Parenchymal necrosis in the brain as a result of the intraventricular infusions was not detected.

Histochemical examination in both vehicle-infused and NGFtreated animals revealed shrinkage of tissue volume in the septum ipsilateral to the fornix lesion (Fig. $2 B$ ). AChE and ChAT staining of the hippocampi in both groups of animals demonstrated a severe reduction of cholinergic fibers in the caudal half of the hippocampus ipsilateral to the fornix lesion, attesting to the completeness of fornix lesions (Fig. 3). As in the rat, cholinergic fibers to the rostral portion of the monkey hippocampus arrive via both the fornix and a ventral trajectory; therefore, AChE staining rostrally was markedly reduced but not eliminated in this region.

ChAT-immunoreactive (ChAT-IR) labeling of cholinergic neurons in all animals resulted in consistent staining between specimens and showed a reduction in the number of cholinergic neurons remaining in the medial septum ipsilateral to the fornix lesion; however, the proportion of remaining neurons was significantly increased in NGF-treated animals compared to vehicle-infused animals. While only $45 \pm 5 \%$ of ChAT-labeled neurons ipsilateral to the fornix lesion remained in vehicleinfused animals (compared to the number of cholinergic neurons on the unlesioned contralateral side; \pm SEM), $80 \pm 6 \%$ of ChATlabeled neurons remained on the lesioned side of the septum in animals receiving NGF treatment ( $p<0.005$; Figs. 4, 6A). Measurements of ChAT-IR neuron numbers obtained by the 2 independent observers correlated highly: $r=+0.98$. Similarly, NGFr-IR labeling in vehicle-infused animals revealed that only $41 \pm 4 \%$ of neurons remained labeled after fornix lesions, while NGF-treated animals showed persistent labeling of $79 \pm 5 \%$ of neurons $(p<0.001$; Figs. $5,6 B$ ).

Of the remaining ChAT- and NGFr-labeled neurons on the side of the fornix lesion in vehicle-infused animals, many were shrunken and pale. In contrast, remaining neurons in NGFtreated animals were generally larger and more intensely labeled than those of vehicle-infused animals. Axonal retraction nodules, which are pathological sequelae of retrogade cell degeneration, were commonly observed in the fornix and septal nuclei of the vehicle-infused animals, but were far less prevalent in NGF-treated animals. Sections through the septum of animals treated with NGF infusions also showed an increase in neurite density, that is, an apparent sprouting response, in the dorsolateral quadrant of the septum, which was apparent both in the AChE preparations and in ChAT and NGFr material.

Nissl-stained sections demonstrated moderate loss of largediameter neurons in the medial septum ipsilateral to the fornix lesion (Fig. 7). Quantification of these changes is in progress.

Measurements of NGF activity in the pump fluid after the 4-week infusion period in 3 animals that received NGF revealed that $76 \%$ of the original concentration of NGF remained, while NGF activity measurements in pump fluid from 2 vehicle-infused animals showed no NGF activity. Thus, NGF appeared to maintain antigenic activity on ELISA during the month-long infusion period. Moreover, NGF concentration measured in the

Figure 3. $A$ and $a$, Photomicrograph of AChE-labeled fibers in hippocampus on nonlesioned side of brain. Normal distribution of fibers is seen, with heavy labeling present in the molecular layer. $g$, granule cell layer; $m$, molecular cell layer. Magnification: $12.5 \times(A), 160 \times(a)$, $B$ and $b$, Severe loss of cholinergic fibers is seen in the hippocampus ipsilateral to the fornix lesion, especially in the outer molecular layer of the dentate gyrus. Reduction in thickness of the dentate layer is also evident. NGF-treated animals showed the same degree of hippocampal denervation as did vehicle-infused animals, because axons of spared ChAT-IR neurons were presumably unable to bridge the fornix lesion cavity. Magnification: $40 \times(B), 160 \times(b)$.

Figure 4. ChAT-IR neuron changes in medial septum after fornix lesions. Low-power photomicrographs demonstrate shrinkage of the septum on the right side of brain, ipsilateral to the fornix transection in both vehicle-infused $(A)$ and NGF-treated $(a)$ animals. Loss of ChAT-IR neuron profiles is seen on the side of the lesion even at this magnification in vehicle-infused animals, with a sparing effect evident in NGF-treated animals $(16 \times)$. Higher magnification of the medial septal region demonstrates prominent loss of ChAT-IR labeling in vehicle-infused animals $(B)$ and sparing in NGF-treated animals $(b)$ on the lesioned side of the brain $(26 \times)$. High magnification of the lesioned side of the septum in vehicle-infused animals $(C)$ demonstrates atrophy (cell shrinkage and light immunolabeling) of cholinergic neurons. Axon retraction nodules are present (arrows). In NGF-trcated animals $(c)$, ncurons are more numerous, larger, and more intensely labeled than those of vehicle-infuscd animals. Magnification, $256 \times$ 

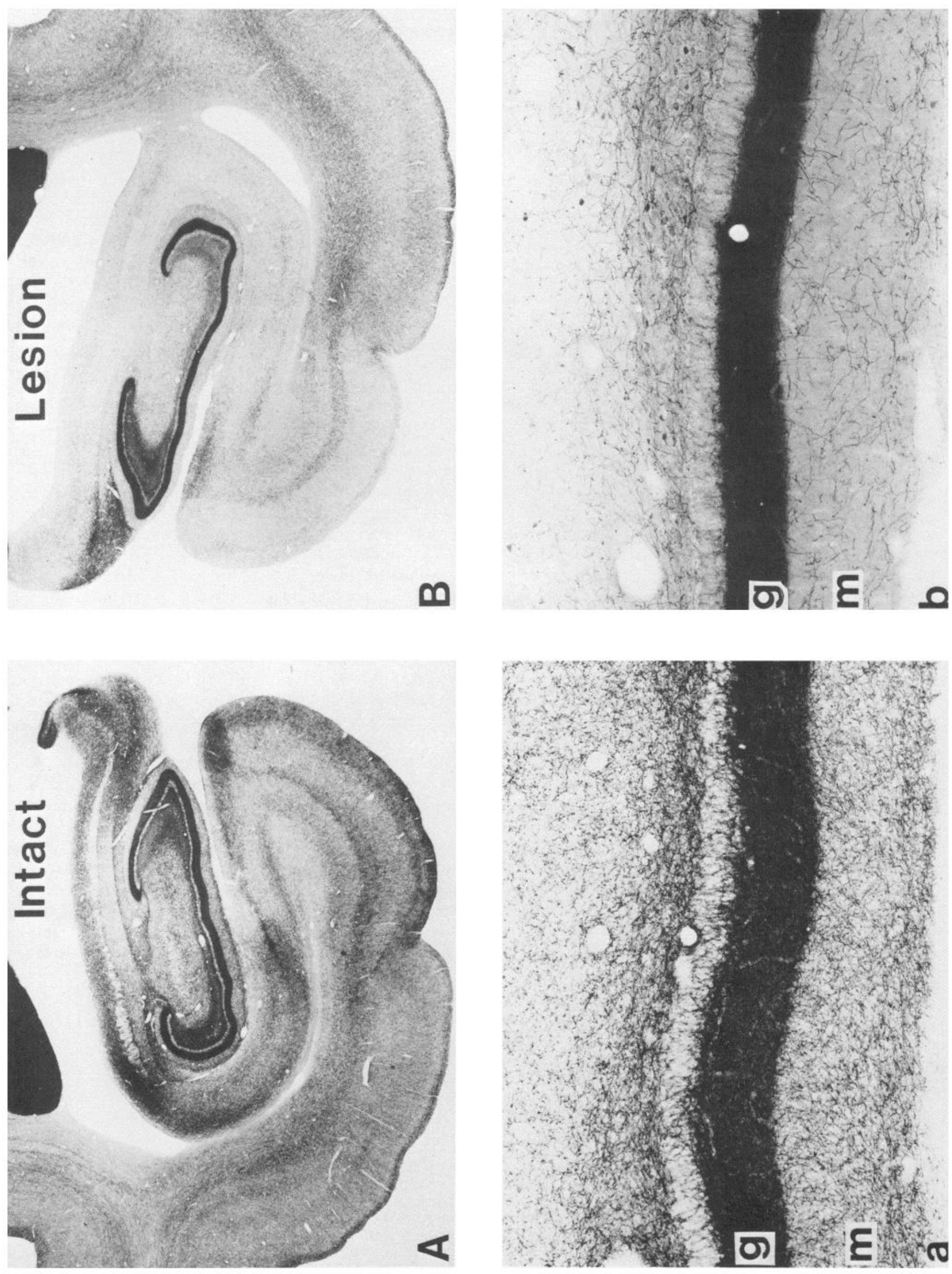

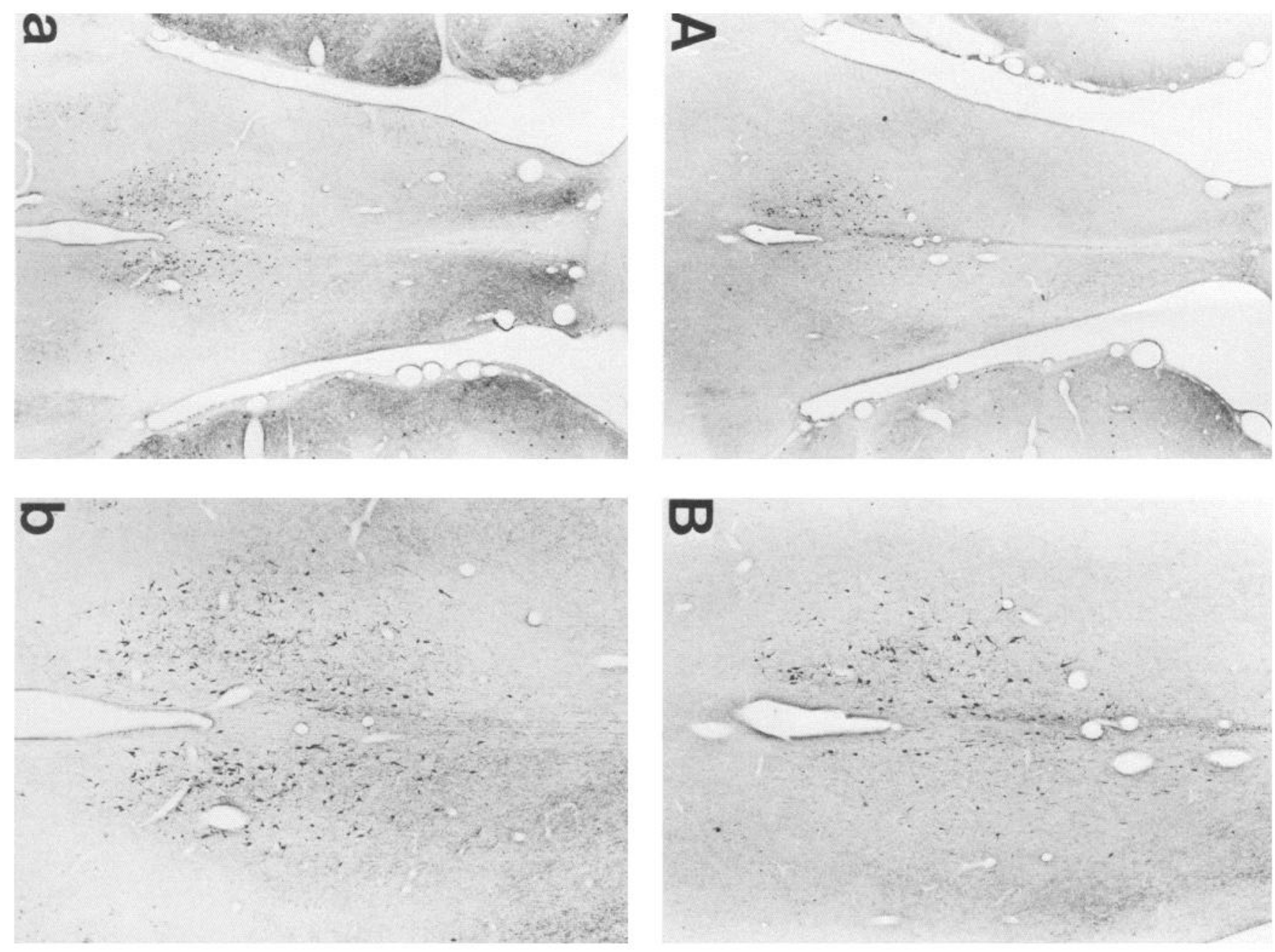

\section{ш}
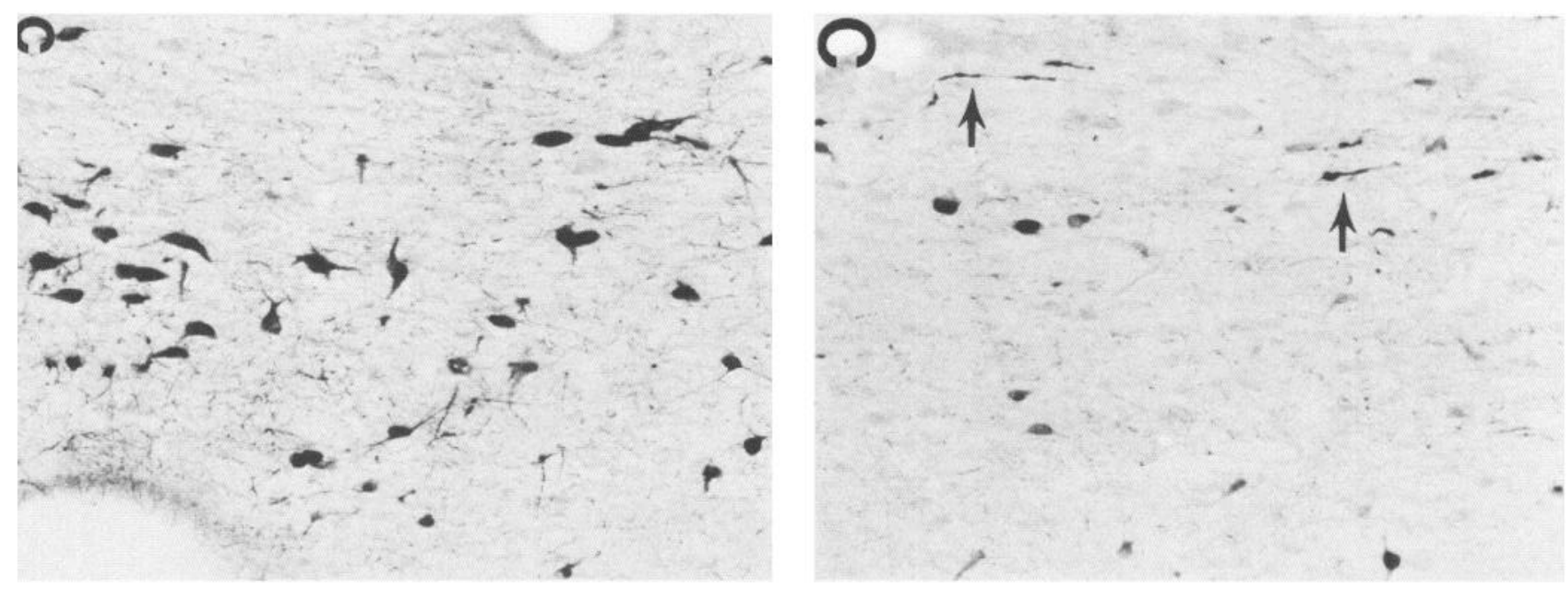

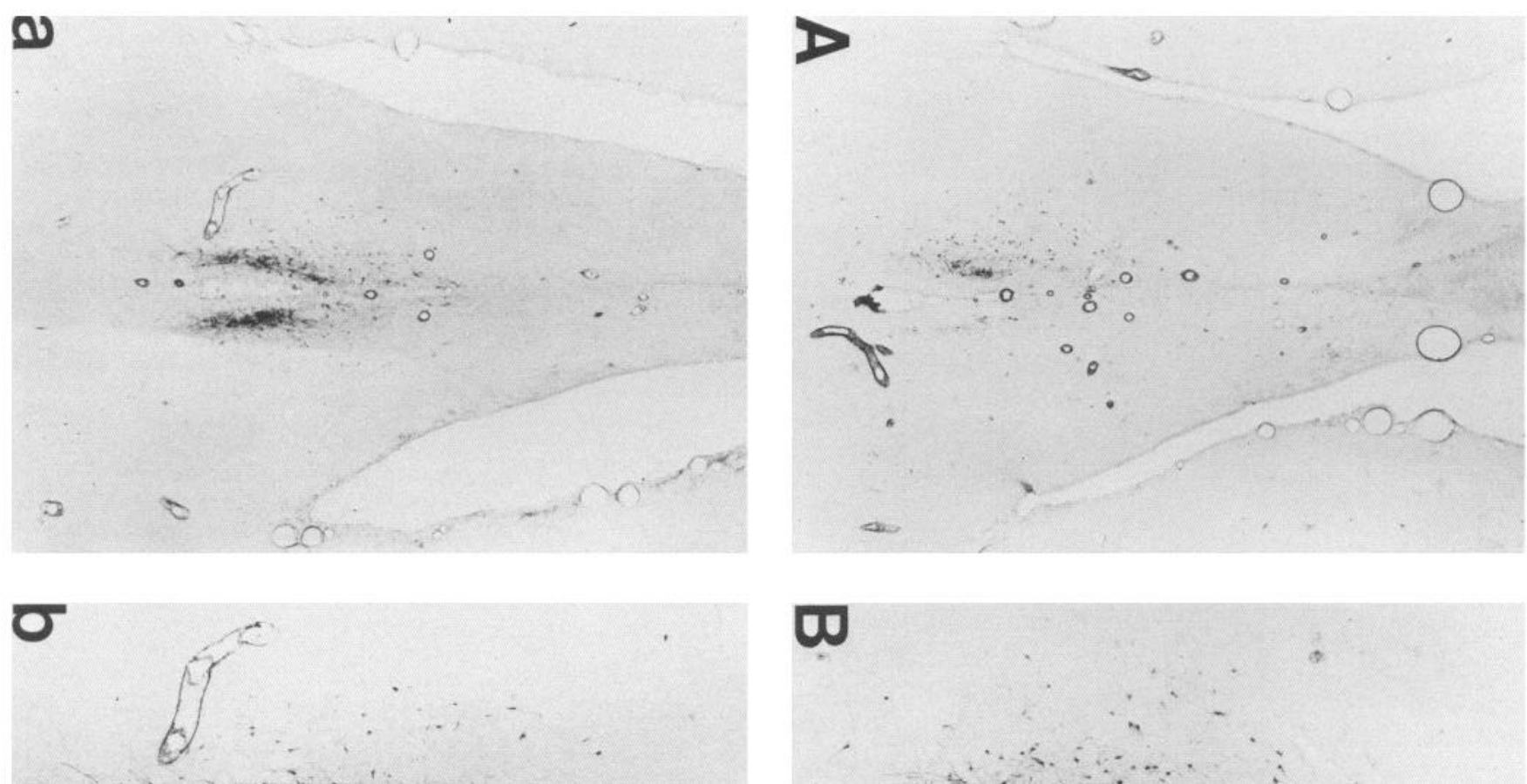

w

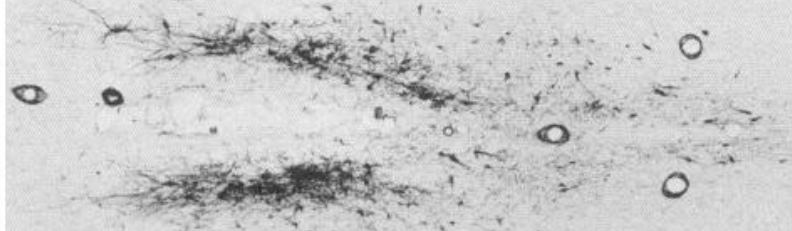

ก
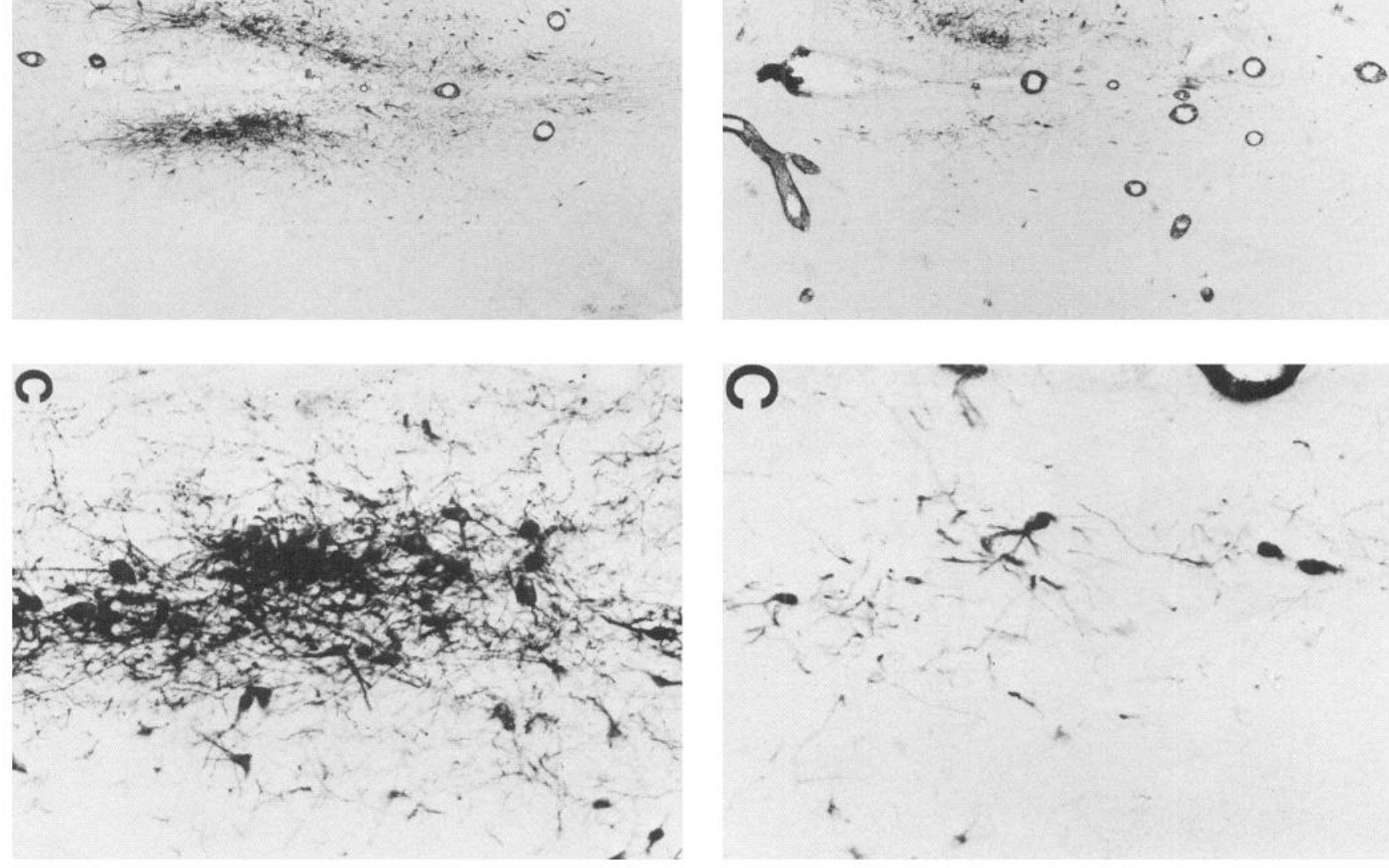

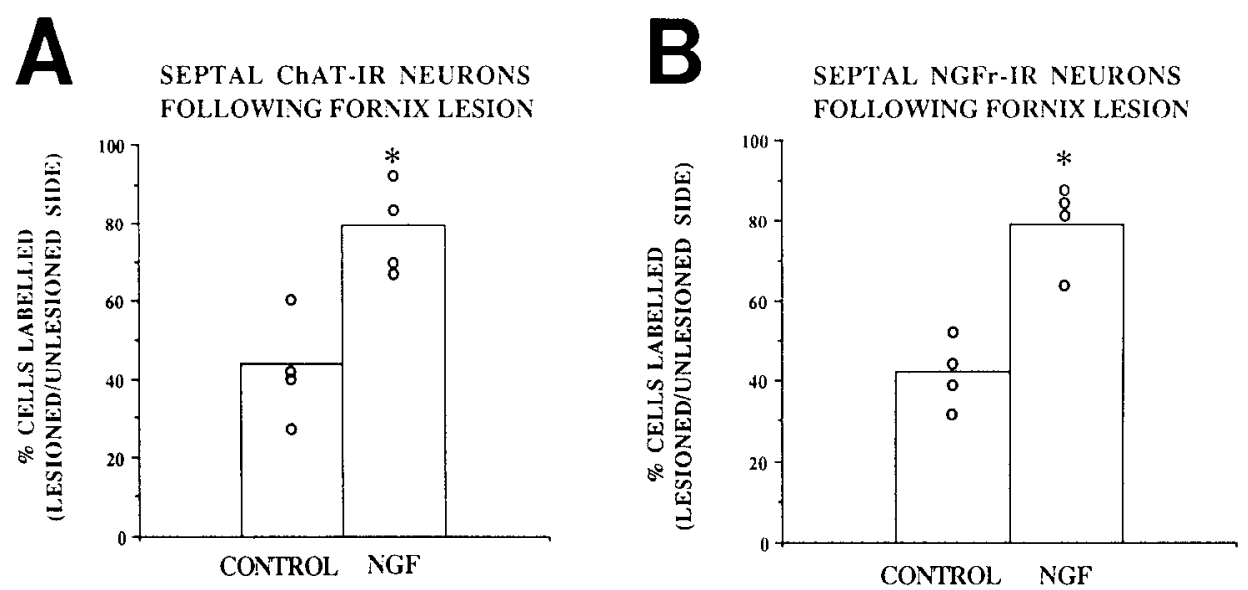

Figure 6. Quantification of ChAT-IR neuron profiles $(A)$ indicates significantly greater proportion of labeled cells remaining in septum of animals receiving NGF treatment $(p<0.005)$ than in vehicle-infused animals. The percentage of remaining neurons was obtained by dividing the total number of ChAT-IR neurons in the septum ipsilateral to the fornix lesion by the total number in the contralateral (unlesioned) septum of the same animal. All sections in which the medial septum was clearly demarcated from the more ventrally located vertical limb of the diagonal band were counted, approximately $10^{3}$ neurons per animal. Quantification of NGFr-IR neuron profiles $(B)$ indicates significantly greater proportion of labeled cells remaining in the septum of animals receiving NGF treatment $(p<0.001)$ than in vehicle-infused animals. The percentage of remaining neurons was calculated as indicated above. Circles indicate individual data points for each animal; asterisks denote significant differences. Standard errors are noted in the text.

CSF taken from the cisterna magna of 2 vehicle-infused animals

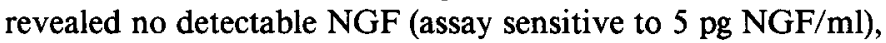
whereas measurements in 2 NGF-treated animals showed levels of 0.88 and $2.13 \mathrm{ng} / \mathrm{ml}$, respectively.

Taken together, these results indicate that chronic infusion of mouse NGF results in elevated levels of NGF in the ventricular system and a significant reduction of retrograde cell changes in a group of basal forebrain cholinergic neurons in the nonhuman primate.

\section{Discussion}

The failure to maintain $100 \%$ of ChAT-IR neurons on the side of the fornix lesion after NGF treatment may be due to several factors. For example, higher doses of NGF may be required. We chose a concentration of $180 \mu \mathrm{g} \mathrm{NGF/ml} \mathrm{based} \mathrm{upon} \mathrm{ex-}$ trapolation of the NGF dose used in rat studies (Gage et al., 1988), taking into consideration the increased volume of the primate CSF space. However, because the diffusion distance to reach cholinergic cell bodies or axotomized neurites may be greater in primates than in rats, still higher NGF concentrations may be required. Alternatively, mouse NGF may not be of sufficient sequence homology to primate NGF to render a maximal effect (Ullirich et al., 1983); experiments using recombinant human NGF in the current model are underway to address this issue. Finally, the degree of retrograde neuron degeneration is influenced by a number of factors, including the distance of axotomy from the cell body (Lieberman, 1971; Torvik, 1976). It is possible that a ceiling effect for prevention of cholinergic neuron degeneration exists, independent of NGF effects, depending upon the degree of mechanical disruption of the axotomized neuron.

The proportion of ChAT- and NGFr-labeled neurons lost in vehicle-infused animals, and the proportion spared in NGFtreated animals, was virtually identical in the current study. This result is consistent with previous anatomical studies demonstrating that $95 \%$ of primate basal forebrain neurons colocalize for ChAT and NGFr and therefore represent the same neuronal populations (Kordower et al., 1988).

Whether primate basal forebrain cholinergic neurons undergo death, permanent atrophy, or a combination of these after fornix lesions is unanswered by the present study. In the rat model, considerable evidence indicates that a combination of neuronal death and atrophy occur in cholinergic basal forebrain neurons after axotomy (Hagg ct al., 1988; Montero and Hefti, 1988; Tuszynski et al., 1990b). A loss of medial septal Nissl staining after fornix lesions was evidenced qualitatively in the present study and previously by others (Daitz and Powell, 1954), suggesting that some neurons die after the fornix lesion. However, whether these lost Nissl neurons are cholinergic cannot be determined by methods used in the present experiment because enzymatic cholinergic markers including ChAT and NGFr may be downregulated following neuronal injury (Reis and Ross, 1973; Lams et al., 1988). Thus, though NGF infusions clearly prevent retrograde degeneration of primate basal forebrain cholinergic neurons, whether or not this effect is "trophic" (deathpreventing) is currently undetermined.

Degeneration of selected neuronal populations characterizes a number of neurodegenerative disorders, including Alzheimer's disease (AD), Parkinson's disease, amyotrophic lateral sclerosis, and others. It is possible that neurotrophic-factor therapy in some of these disorders may be beneficial in preventing neuronal degeneration (Appel, 1981). Disturbance in cholinergic function appears to be an important but partial characteristic of $A D$, in which multiple populations of neurons undergo degeneration,

Figure 5. NGFr-IR neuron changes in medial septum after fornix lesions. Results similar to those observed with ChAT labeling are present at all magnifications in vehicle-infused $(A-C)$ and NGF-treated $(a-c)$ animals. In addition, enhanced labeling of NGFr-IR neuronal processes is seen on the intact (left) side of medial septum in NGF-treated animals $(a, b)$, suggesting potential upregulation of NGFr levels on the intact side of the brain induced by contralateral NGF intraventricular infusions. Magnification: $A$ and $a, 16 \times ; B$ and $b, 51 \times ; C$ and $c, 256 \times$. 


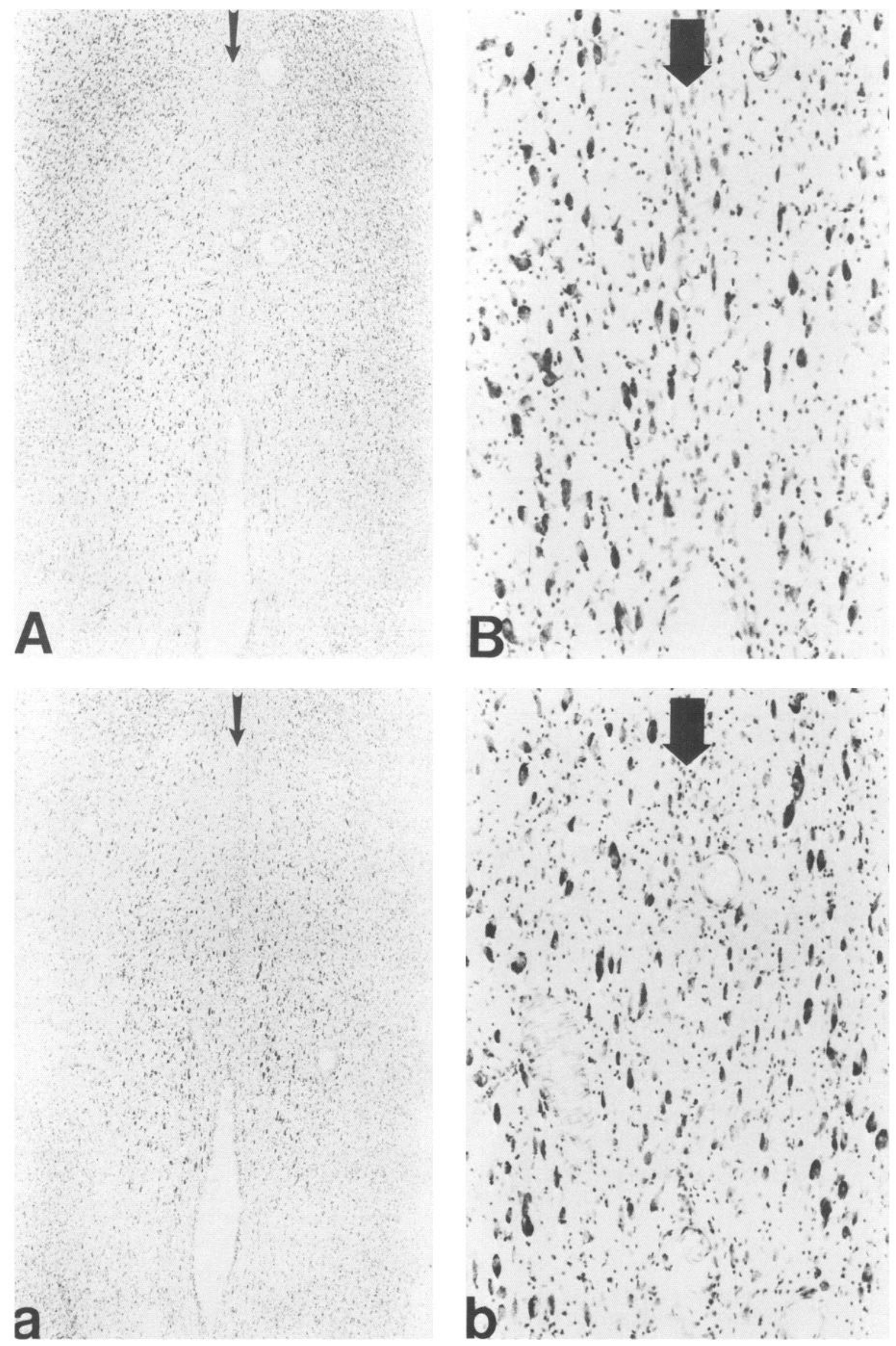

Figure 7. Nissl-stained sections of medial septum in vehicle-infused and NGF-treated animals. A generalized loss of large-diameter neurons is evident on the right side of the septum, ipsilateral to the fornix lesion $(A, B)$. Neuronal loss is reduced after NGF treatment $(a, b)$. Magnification: $A$ and $a, 38 \times ; B$ and $b, 152 \times$. Arrows indicate the midline. 
including cholinergic, noradrenergic, and serotonergic neurons, among others (for review, see Bartus et al., 1982; Coyle et al., 1983). Loss of cholinergic basal forebrain neurons appears to be of particular importance in $\mathrm{AD}$, however, because the degree of cholinergic degeneration has been correlated both with the presence of pathological markers of AD in the brain (i.e., density of senile plaques in the brain) and with the severity of dementia that comprises the predominant clinical manifestation of this disease (Bartus et al., 1982; Coyle et al., 1983). The cholinergic system also plays a prominent role in memory, and memory loss is a kcy clinical fcaturc of AD. Mild improvement in some features of cognitive dysfunction in $\mathrm{AD}$ have resulted from augmentation of cholinergic function [e.g., treatment with anticholinesterases and ACh precursors (Bartus et al., 1982; Coyle et al., 1983; Sunde and Zimmer, 1983; Sunderland et al., 1988)]. In animal models, deficits in memory tasks occur after pharmacological cholinergic blockade or lesions to cholinergic neurons and are partially reversed by restoration of cholinergic influence (Bartus et al., 1982; Coyle et al., 1983; Sunderland et al., 1988). Further, strains of aged rats (e.g., Fisher, SpragueDawley) demonstrate age-related degeneration of cholinergic basal forebrain neurons and deficits on behavioral mnemonic tasks (Bartus et al., 1982; Coyle et al., 1983) that can be improved with NGF infusions (Gage et al., 1983; Fischer et al., 1987). The correlation between memory, cholinergic neurons, and NGF has led to the hypothesis that NGF may be of therapeutic benefit in AD. In the current study, we have shown that lesion-induced cholinergic neuron degeneration is preventable in primates by NGF therapy. NGF may also be of benefit in preventing cholinergic neuron degeneration in $\mathrm{AD}$, which could in turn improve some cognitive deficits that are characteristic of this disorder (Bartus et al., 1982; Coyle et al., 1983; Hefti and Weiner, 1986). Studies of NGF protein content, mRNA levels, and NGFr changes both in normal aging and in AD will provide additional useful data to address this question. However, NGF may still be beneficial to dysfunctional cholinergic neurons even if deficient synthesis or enhanced degradation of NGF is not a primary event in a disorder such as $A D$, for example, by augmenting the function of remaining intact cholinergic neurons.

It is anticipated that neurotrophic-factor intervention would be most efficacious early in the course of AD when a larger population of cholinergic neurons remains intact as a substrate for NGF action; beyond a certain stage of degeneration, the loss of cholinergic populations might render NGF therapy ineffective. Earlier intervention will depend upon development of enhanced diagnostic markers for the disease. The possibility has recently been raised that NGF might promote aberrant neurite changes in the brain (Mobley et al., 1988), and careful examination of the effects of chronic NGF infusion in the aged nonhuman primate will be essential. Therefore, while neurotrophicfactor therapy may offer promise as a therapeutic tool in some neurodegenerative disorders, prudence suggests that clinical trials should await the presentation of additional experimental support, especially in a primate model system. The results of the present study are a useful but preliminary step in this direction.

\section{References}

Appel SH (1981) A unifying hypothesis for the cause of amyotrophic lateral sclerosis, parkinsonism, and Alzheimer disease. Ann Neurol 10:499-505.
Ayer LeLievre CS, Abendal T, Olsen L, Seiger A (1983) Localization of NGF-like immunoreactivity in rat neurons tissue. Med Biol 61: 296-304.

Bartus R, Dean RL, Beer C, Lippa AS (1982) The cholinergic hypothesis of geriatric memory dysfunction. Science 217:408-417.

Batchelor PE, Armstrong DM, Blaker SM, Gage FH (1989) Nerve growth factor receptor and choline acetyltransferase colocalization in neurons within the rat forebrain: response to fimbria-fornix transection. J Comp Neurol 284:187-204.

Collins F, Dawson A (1983) An effect of nerve growth factor on parasympathetic neurite outgrowth. Proc Natl Acad Sci USA 80:20912094.

Coyle JT, Price PH, Delong MR (1983) Alzheimer's disease: a disorder of cortical cholinergic innervation. Science 219:1184-1189.

Daitz HM, Powell TPS (1954) Studies on the connexions of the fornix system. J Neurol Neurosurg Psychiatry 17:75-82.

Fischer W, Wictorin K, Bjorklund A, Williams LR, Varon S, Gage FH (1987) Amelioration of cholinergic neuron atrophy and spatial memory impairment in aged rats by nerve growth factor. Nature 329:6568.

Gage FH, Dunnett SB, Stenevi U, Bjorklund A (1983) Aged rats: recovery of motor impairments by intrastriatal nigral grafts. Science 221:966-969.

Gage FH, Wictorin K, Ficher W, Williams LR, Varon S, Bjorklund A (1986) Life and death of cholinergic neurons: in the septal and diagonal band region following complete fimbria-fornix transection. Neuroscience 19:241-255.

Gage FH, Armstrong DM, Williams LR, Varon S (1988) Morphologic response of axotomized septal neurons to nerve growth factor. J Comp Neurol 269:147-155.

Greene L, Shooter EMN (1980) The nerve growth factor: biochemistry, synthesis, and mechanism of action. Annu Rev Neurosci 3:353402.

Gundersen RW, Barrett JN (1980) Characterization of the turning response of dorsal root neurites toward nerve growth factor. J Cell Biol 87:546-554.

Hagg T, Manthorpe M, Vahlsing HL, Varon S (1988) Delayed treatment with nerve growth factor reverses the apparent loss of cholinergic neurons after acute brain damage. Exp Neurol 101:303-312.

Hefti F (1986) Nerve growth factor (NGF) promotes survival of septal cholinergic neurons after fimbrial transection. J Neurosci 6:21552162.

Hefti F, Weiner WJ (1986) Nerve growth factor and Alzheimer's disease. Ann Neurol 20:275-281.

Kordower JH, Bartus RT, Bothwell M, Schatteman G, Gash DM (1988) Nerve growth factor receptor immunoreactivity in the non-human primate (Cebus apella): distribution, morphology, and colocalization with cholinergic enzymes. J Comp Neurol 277:465-486.

Kromer LF (1987) Nerve growth factor treatment after brain injury prevents neuronal death. Science 235:214-216.

Lams BE, Isacson O, Sofroniew MV (1988) Disappearance of transmitter-associated enzyme staining does not correlate with death of axotomized cholinergic neurons. Soc Neurosci Abstr 14:366.

Levi-Montalcini $R$ (1987) The nerve growth factor 35 years later. Science 237:1154-1162.

Levi-Montalcini R, Meyer H, Hamburger V (1954) In vitro experiments on the effects of mouse sarcoma 180 and 37 on the spinal and sympathetic ganglia of the chick embryo. Cancer Res 14:49-57.

Lieberman AR (1971) The axon reaction: a review of the principal features of perikaryal responses to axon injury. Int Rev Neurobiol $14: 49-124$

Mobley WC, Neve RL, Prusiner SB, McKinley MP (1988) Nerve growth factor induces gene expression for prion- and Alzheimer's beta-amyloid proteins. Proc Natl Acad Sci USA 85:9811-9815.

Montero CN, Hefti F (1988) Rescue of lesioned septal cholinergic neurons by nerve growth factor: specificity and requirement for chronic treatment. J Neurosci 8:2986-2999.

Reis DJ, Ross RA (1973) Dynamic changes in brain dopamine-Bhydroxylase activity during anterograde and retrograde reactions to injury of central noradrenergic axons. Brain Res 57:307-326.

Richardson PM, Verge Isse VMK, Riopelle RJ (1986) Distribution of neuronal receptors for nerve growth factor in the rat. J Neurosci 6 : 2312-2321.

Schatteman GC, Gibbs L, Lanahan AA, Claude P, Bothwell M (1988) Expression of NGF receptor in the developing and adult primate central nervous system. J Neurosci 8:860-873. 
Schwab ME, Otten U, Agid Y, Thoenen H (1979) Nerve growth factor (NGF) in the rat CNS: absence of specific retrograde axonal transport and tyrosine hydroxylase induction in locus coeruleus and substantia nigra. Brain Res 168:473-483.

Scott SM, Tarris R, Eveleth D, Mansfield H, Weichsel ME, Fisher DA (1981) Bioassay detection of mouse nerve growth factor (mNGF) in the brain of adult mice. J Neurosci Res 6:653-658.

Seiler M, Schwab ME (1984) Specific retrograde transport of nerve growth factor (NGF) from cortex to nucleus basalis in the rat. Brain Res 300:33-39.

Sheldon DL, Reichardt LF (1986) Studies on the expression of the beta-nerve growth factor (NGF) gene in the central nervous system; level and regional distribution of NGF mRNA suggest that NGF functions as a trophic factor for several distinct populations of neurons. Proc Natl Acad Sci USA 83:2714-2718.

Sunde NAa, Zimmer J (1983) Cellular, histochemical and connective organization of the hippocampus and fascia dentata transplanted to different regions of immature and adult rat brains. Dev Brain Res 8: 165-191.

Sunderland T, Tariot PN, Newhouse PA (1988) Differential responsivity of mood, behavior, and cognition to cholinergic agents in elderly neuropsychiatric populations. Brain Res Rev 13:371-389.

Taniuchi M, Johnson EM (1985) Characterization of the binding properties and retrograde axonal transport of monoclonal antibody directed against the rat nerve growth factor receptor. J Cell Biol 101: $1100-1106$.
Thoenen H, Barde YA (1980) Physiology of nerve growth factor. Physiol Rev 60:1284-1335.

Torvik A (1976) Central chromatolysis and the axon reaction: a reappraisal. Neuropath Appl Neurobiol 2:423-432.

Tuszynski MH, Buzsaki G, Gage FH (1990a) NGF infusions combined with fetal hippocampal grafts enhance reconstruction of the lesioned septo-hippocampal projection. Neuroscience 36:32-44.

Tuszynski MH, Armstrong DA, Gage FH (1990b) Basal forcbrain cell loss following fimbria/fornix transection. Brain Res 508:241-248.

Ullrich A, Gray A, Berman C, Dull TJ (1983) Human beta-nerve growth factor gene sequence highly homologous to that of mouse. Nature 303:821-825.

Wainer BH, Levey AI, Rye DB, Mesulam M, Mufson EJ (1985) Cholinergic and non-cholinergic septohippocampal pathways. Neurosci Lett 54:45-52.

Weskamp G, Otten U (1987) An enzyme-linked immunoassay for nerve growth factor (NGF): a tool for studying regulatory mechanisms involved in NGF production in brain and in peripheral tissues. $J$ Neurochem 48:1779-1786.

Williams LR, Varon S, Peterson GM, Wictorin K, Fisher W, Bjorklund A, Gage FH (1986) Continuous infusion of nerve growth factor prevents basal forebrain neuronal death after fimbria-fornix transcction. Proc Natl Acad Sci USA 83:9231-9235. 